\title{
Calculation of Optimal Selexen Dosage to Enrich Bakery Products with Selenium
}

\author{
Natalia Naumova, Aleksandr Lukin*, and Abduvali Toshev \\ Federal State Autonomous Educational Institution of Higher Education, South \\ Ural State University (National Research University), Chelyabinsk, 454080, \\ Russia \\ *Corresponding author. E-mail: lukin3415@gmail.com \\ https://doi.org/10.12982/CMUJNS.2019.0022
}

\begin{abstract}
It is possible to solve selenium (Se) deficiency among the population by using bread enriched with selenium; the goal of this study was to calculate the optimal dosage of selexen for this purpose. It was established for the first time that selenium losses during the production of bakery products using preferment and accelerated methods are within 45-55\% of the applied dosage. One day after baking, Se losses in unpackaged articles obtained by the accelerated method are equal to 2-24\%, and those obtained through pre-ferment - 2-28\%. With an increase in the initial dosage of selenium, the percentage of loss decreases. With 50 and $100 \mu \mathrm{g} 100 \mathrm{~g}^{-1}$ of Se in packaged products obtained from pre-ferment, the content of the microelement does not change on the third day of storage; with other dosages of selenium, the losses are 9-19\%; in packaged products obtained by the accelerated method, the Se losses are from 4 to $24 \%$ with the highest trace element retained at the initial dosages of 50 and $100 \mu \mathrm{g} 100 \mathrm{~g}^{-1}$. Our recommendations are: in the production of bakery products without packaging - the accelerated production method for the introduction of $174 \mu \mathrm{g} 100 \mathrm{~g}^{-1}$ or the pre-ferment method for $220 \mu \mathrm{g}$ $100 \mathrm{~g}^{-1}$; in the production of packaged goods - the pre-ferment production method for $174 \mu \mathrm{g} \quad 100 \mathrm{~g}^{-1}$ selenium or the accelerated production method for $220 \mu \mathrm{g} 100 \mathrm{~g}^{-1}$.
\end{abstract}

Keywords: Quality, Selenium, Food 


\section{INTRODUCTION}

Hyperselenosis most often develops in individuals living in areas with a pronounced lack of selenium in soil, water, and food (Natasha et al., 2018). Biogeochemical regions with a lack of selenium are often found in the NonBlack Earth region stretching from the northeastern borders of the USA across the whole of Europe - the north of Germany, Holland, Denmark, Poland, through the Baltic countries, and Central Russia - to the Urals, then across Siberia to the eastern borders of Russia (Burtseva, 2012; Fordyce, 2013; Erdenetsogt et al., 2014; Stoffaneller and Morse, 2015; Zhang et al., 2018). Natural geochemical features of the territories, being a constant influence on the human body, can cause the development of endemic diseases.

Selenium is an essential micronutrient and is of paramount importance in protecting the body from oxidative stress (Fairweather-Tait et al., 2011; Sobolev et al., 2018). Its immunostimulating properties have been established, and the positive influence on human reproductive function has been proved (Mahlapuu et al., 2014, Roman et al., 2014; Aryee and Boye, 2015). Selenium compounds are effective as anti-cancer agents (Hu et al., 2012; Jablonska and Vinceti, 2015; Nociek et al., 2015; Vinceti et al., 2018). Health risks associated with selenium deficiency can pose a serious threat to the human body.

It is possible to use bakery products obtained from wheat grain with high (natural) selenium content (Hart et al., 2011; Burtseva et al., 2012; Glotova et al., 2013; Gupta and Gupta, 2016) or bakery products enriched with this trace element to solve selenium deficiency. Due to their high nutritional value, excellent taste and aromatic proper-ties, good digestibility and saturation, ease of preparation, and cheapness, bakery products are the most popular products and can serve as the most convenient objects with which to adjust the nutritional value of finished products (Ilyina, 2012; Spirichev et al., 2012; Ilyina et al., 2013; Tarasova, 2014; Lazo-Vélez et al., 2015).

The purpose of this research was to calculate the optimum dosages for enriching bakery products with selenium.

\section{MATERIALS AND METHODS}

\section{Preliminary experiment calculation}

The daily requirements for selenium (Se) were taken from the current standards (Tutelyan, 2009), according to which the physiological need (PN) for an adult is $70 \mu \mathrm{g} \mathrm{day}^{-1}$ and the upper permissible level of consumption is $300 \mu \mathrm{g}$ day $^{-1}$. In Russia, the additional dose of selenium intake per day is $100 \mu \mathrm{g}$, and in the US and other countries - 200 or $300 \mu \mathrm{g}$ (EFSA Panel on Dietetic Products, 
2014; Rayman et al., 2018). The safe upper limit for selenium compound consumption for adults long-term is $819 \pm 126 \mu \mathrm{g}_{\text {day }}{ }^{-1}$. The response increase in glutathione peroxidase activity to selenium intake occurs when the microelement is introduced in an amount of $40 \mu \mathrm{g}$ per day ${ }^{-1}$ and higher (EFSA Panel on Dietetic Products, 2014).

Since products with less than $30 \%$ of the daily requirement of a particular mineral cannot effectively correct dietary deficiencies (Kodentsova and Vrzhesinskaya, 2008; Kodentsova et al., 2010; Skalickova et al., 2017), the selexen dosages were selected in such a way that the consumption of the average daily portion of the enriched product would satisfy $30-50 \%$ of the physio-logical needs of the adult organism in selenium (Table 1).

Table 1. Levels of enrichment of the bakery product.

\begin{tabular}{lccccc}
\hline \multirow{2}{*}{ Parameter } & \multicolumn{5}{c}{ Amount of selexen, $\boldsymbol{\mu g} \mathbf{~ 1 0 0 ~} \mathbf{~ g}^{-1}$ of product } \\
\cline { 2 - 6 } & $\mathbf{8 7}$ & $\mathbf{1 3 0}$ & $\mathbf{1 7 4}$ & $\mathbf{2 2 0}$ & $\mathbf{4 3 5}$ \\
\hline $\begin{array}{l}\text { Amount of selenium added } \\
\text { with selexen }\end{array}$ & 20 & 30 & 40 & 50 & 100 \\
\hline
\end{tabular}

\section{Applied research materials}

A basic 'Gorodskaya' roll recipe was used for the control sample (composition: wheat flour, pressed yeast, salt, granulated sugar, margarine, water), made with traditional pre-ferment and accelerated (using concentrated lactic acid fermenter and the 'Mazhimiks' enhancer) production methods, and for the experiment - the same recipe with the introduction of a selenium-containing additive - selexen.

Selexen (produced by Medbiopharm, Obninsk, Kaluga region) is a synthetic heterocyclic organic selenium compound (containing no less than $95 \%$ selenopyran) and is a stable beige-colored crystalline powder with a weak specific smell, soluble in dairy cream. Selexen has a selenium con-tent of 23$24 \%$. Selexen can be used as an antioxidant drug with a wide spectrum of action, modeling and stimulating the immune system and acting as an adaptogenic, anti-stress, anti-carcinogenic, antimutagenic, and antiviral drug (Report on the study of the functional suitability of the domestic organic compound seleniumselexen, 2000).

\section{Specifics of production and storage of model samples of bakery products}

Selexen was dissolved in melted margarine and added in the kneading stage of production. The weight of the finished loaves was $150 \pm 5 \mathrm{~g}$. Some of the ready-made rolls were packed in perforated polypropylene film. Roll samples were stored at an air temperature of $20 \pm 2^{\circ} \mathrm{C}$ and a relative humidity of air no more than $75 \%$. 


\section{Applied research methods}

The selenium content was determined through the fluorimetric method. The method involves sample mineralization with the aim of transferring selenium from organic and inorganic forms to selenite ion, carrying out the reaction of selenite ion with 2,3-diaminonaphthalene reagent in an acidic medium to form 4, 5-benzopiazoselenol extracted with hexane, and measuring the fluorescence intensity extract on 'Fluorat-2' fluid analyzer (Skurikhin and Tutelyan, 1998).

Statistical analysis was performed in Microsoft Excel XP and Statistica 8.0. Statistical error did not exceed 5\% (95\% confidence level). Regression analysis was completed on the results using the Statgraphics Centurion package.

\section{RESULTS}

One of the most significant indicators of quality for an enriched product is its ability to maintain its functional properties throughout its shelf life. Many micronutrients are destroyed by thermal treatment and by light and oxygen, so one of the tasks of our study was to research the safety of selenium in the production and storage of bakery products enriched with this trace element and to determine the optimal dosage. Selenium content was determined by taking the regulated shelf life of products into account -24 hours for products without packaging, and 72 for those in packaging. The results of studies on selenium safety in the production and storage of the analyzed products are presented in Table 2.

Se content was not determined in the control samples of bakery products at the end of the storage period because of its low concentration in freshly prepared products, $150 \mathrm{~g}$ of which satisfies just $1.5 \%$ of the physiological requirement for this microelement. 
Table 2. Changes in selenium content in 'Gorodskaya' roll samples.

\begin{tabular}{|c|c|c|c|c|c|c|}
\hline \multirow{4}{*}{$\begin{array}{l}\text { Amount } \\
\text { of } \\
\text { selenium } \\
\text { added } \\
\text { with } \\
\text { selexen, } \\
\mu \mathrm{g} 100 \mathrm{~g}^{-1}\end{array}$} & \multicolumn{6}{|c|}{ Selenium content in the tested products, $\mu \mathrm{g} 100 \mathrm{~g}^{-1}$} \\
\hline & \multirow{2}{*}{\multicolumn{2}{|c|}{$\begin{array}{c}\text { In the production process } \\
\text { (after baking) }\end{array}$}} & \multicolumn{4}{|c|}{ During storage } \\
\hline & & & \multicolumn{2}{|c|}{24 hours } & \multicolumn{2}{|c|}{72 hours } \\
\hline & $\begin{array}{l}\text { without in } \\
\text { package package }\end{array}$ & $\%$ of $P N$ & $\begin{array}{l}\text { without } \\
\text { package }\end{array}$ & $\%$ of $P N$ & $\begin{array}{l}\text { in } \\
\text { package }\end{array}$ & $\%$ of $P N$ \\
\hline \multicolumn{7}{|c|}{ Accelerated method: } \\
\hline control & $0.7 \pm 0.1$ & 1.0 & $\begin{array}{c}\text { not } \\
\text { detected }\end{array}$ & - & $\begin{array}{c}\text { not } \\
\text { detected }\end{array}$ & - \\
\hline 20 & $11.0 \pm 0.2$ & 15.7 & $8.9 \pm 0.2$ & 12.7 & $9.0 \pm 0.2$ & 12.8 \\
\hline 30 & $17.0 \pm 0.4$ & 24.3 & $12.8 \pm 0.4$ & 18.3 & $12.9 \pm 0.4$ & 18.4 \\
\hline 40 & $19.0 \pm 0.4$ & 27.1 & $17.0 \pm 0.3$ & 24.3 & $15.0 \pm 0.2$ & 21.4 \\
\hline 50 & $23.0 \pm 0.5$ & 32.8 & $20.0 \pm 0.4$ & 28.6 & $21.0 \pm 0.3$ & 30.0 \\
\hline 100 & $46.1 \pm 0.7$ & 65.8 & $45.0 \pm 0.3$ & 64.3 & $44.0 \pm 0.4$ & 62.8 \\
\hline \multicolumn{7}{|c|}{ Pre-ferment method: } \\
\hline control & $0.7 \pm 0.1$ & 1.0 & $\begin{array}{c}\text { not } \\
\text { detected }\end{array}$ & - & $\begin{array}{c}\text { not } \\
\text { detected }\end{array}$ & - \\
\hline 20 & $10.0 \pm 0.6$ & 14.3 & $8.4 \pm 0.2$ & 12.0 & $8.8 \pm 0.2$ & 12.6 \\
\hline 30 & $17.0 \pm 0.3$ & 24.3 & $12.7 \pm 0.4$ & 18.1 & $13.7 \pm 0.4$ & 19.6 \\
\hline 40 & $21.0 \pm 0.2$ & 30.0 & $15.0 \pm 0.4$ & 21.4 & $19.0 \pm 0.3$ & 27.1 \\
\hline 50 & $22.0 \pm 0.4$ & 31.4 & $21.0 \pm 0.2$ & 30.0 & $22.0 \pm 0.4$ & 31.4 \\
\hline 100 & $45.0 \pm 0.5$ & 64.3 & $44.0 \pm 0.4$ & 62.8 & $45.0 \pm 0.2$ & 64.3 \\
\hline
\end{tabular}

When investigating the relationship between Se content after baking and the applied dosage (Figure 1), as well as Se content during storage of unpackaged (Figure 3) and packaged products (Figure 5) and the applied dosage in both methods of production, a significant and adequate correlation was established between the variables. The constructed linear models describe $99 \%$ of variability of variables with a statistically significant correlation coefficient of 0.99 , which indicates a close linear relationship between the parameters studied.

When comparing the concentrations of Se in the rolls of both methods of production, a nonparametric Kolmogorov-Smirnov test was used (Byuyul and Cephil, 2005), showed no statistically significant differences between the distributions of the observed results at a significance level of 0.05 (Figures 2, 4, $6)$. 

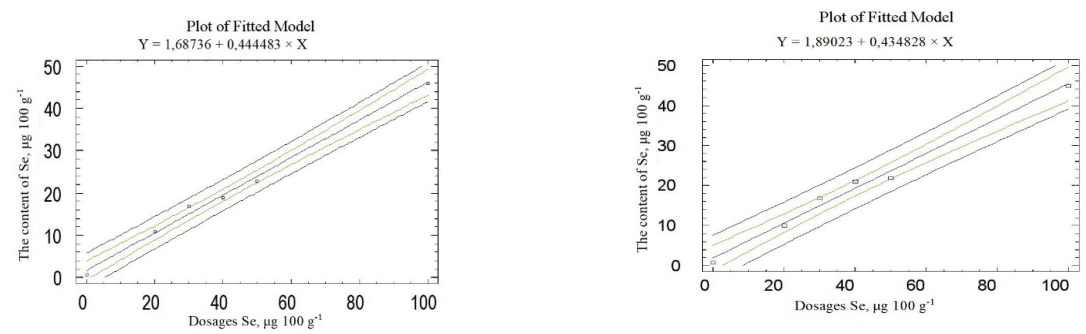

a) accelerated mode of production

b) pre-ferment mode of production.

Figure 1. Dependence of selenium content in the finished product (after baking) on the dosage of the microelement.

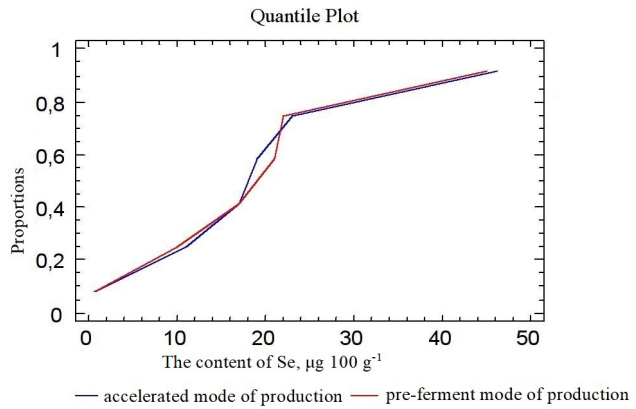

Figure 2. Comparative analysis of the selenium content in finished products (after baking) of the accelerated and pre-ferment production methods. 


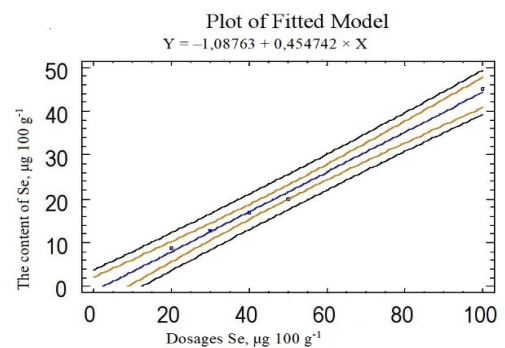

a) accelerated mode of production

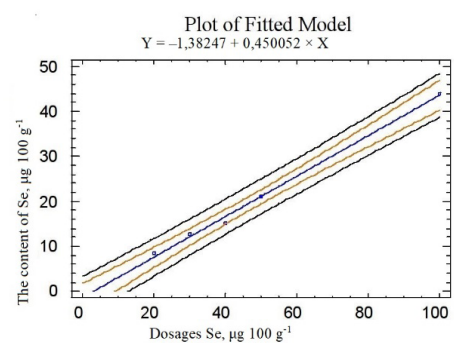

b) pre-ferment mode of production.

Figure 3. Dependence of the selenium content in the finished product (during storage without packaging) on the initial microelement dosage.

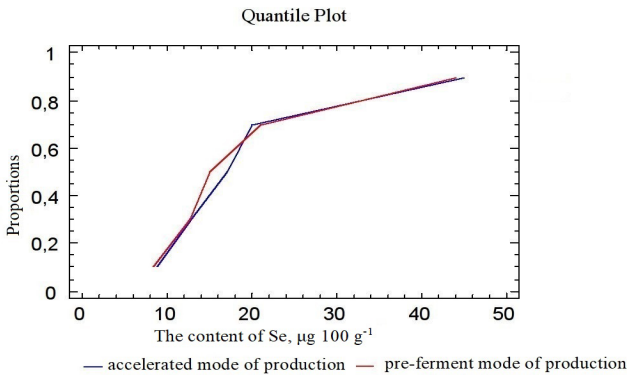

Figure 4. Comparative analysis of selenium content in finished products (during storage with-out packaging) of the accelerated and pre-ferment production methods.
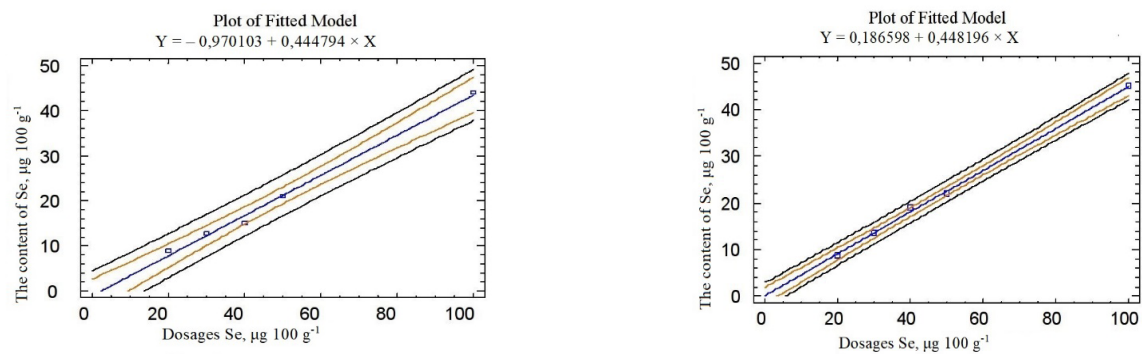

a) accelerated mode of production b) pre-ferment mode of production.

Figure 5. Dependence of the selenium content in the finished product (during storage in pack-age) on the initial microelement dosage. 


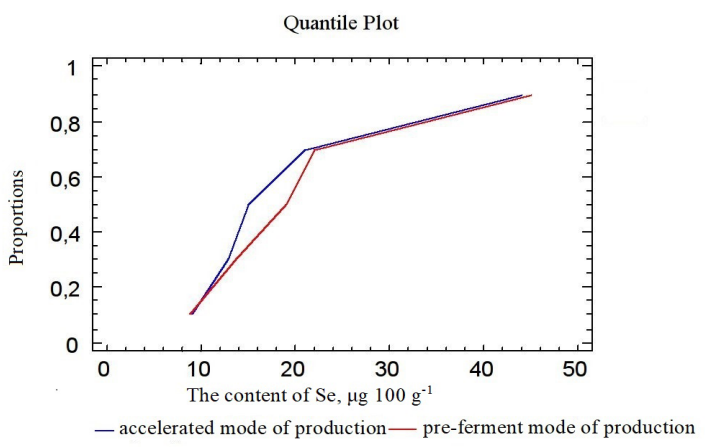

Figure 6. Dependence of the selenium content in the finished product (during storage in pack-age) on the initial microelement dosage.

When investigating the relationship between Se losses during the production process and the dose introduced, a pronounced positive correlation was found between these variables with significant correlation coefficients $(0.76$ for the accelerated production method and 0.64 for the pre-ferment method). Nonlinear regression dependencies (Figure 7) accumulate 57\% and $41 \%$ variability of variables, respectively, which requires some caution when using these models for forecasting (Byuyul and Cephil, 2005).
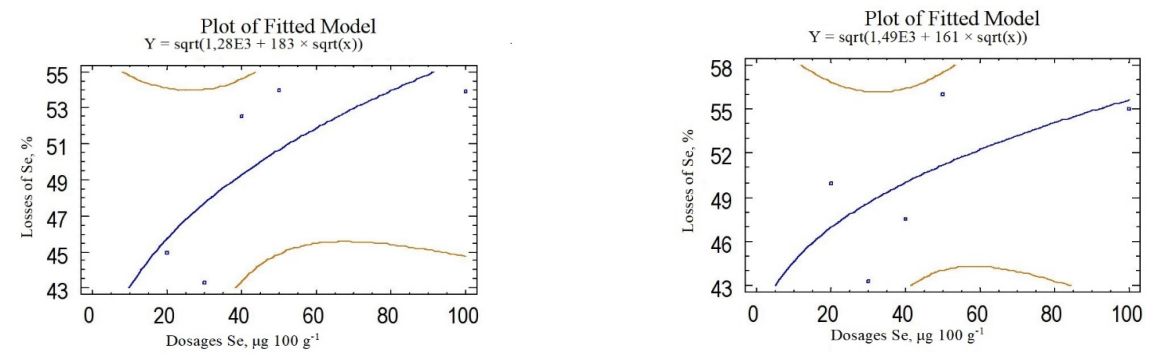

a) accelerated mode of production b) pre-ferment mode of production.

Figure 7. Dependence of losses of selenium in the process of production of bakery products on the initial microelement dosage. 
The average values of Se lost during production depending on the dosage for the rolls of both production methods were also compare. At a significance level of 0.05, the Mann-Whitney criterion (Byuyul and Cephil, 2005) confirmed the absence of statistically significant differences between these parameters, therefore, there are no grounds for concluding that there are differences in similar indicators of the investigated production methods.

Investigation of the relationship between Se losses during the storage of unpackaged products and the dosage of the microelement (Figure 8) showed a significant and adequate correlation in both production methods.

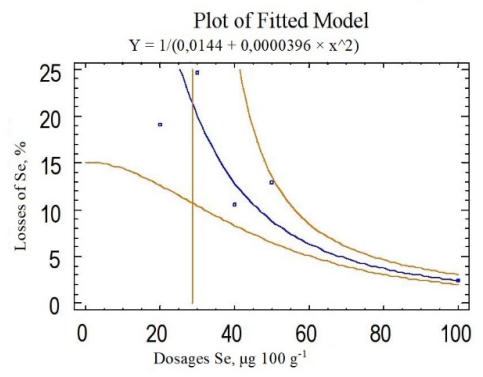

a) accelerated mode of production

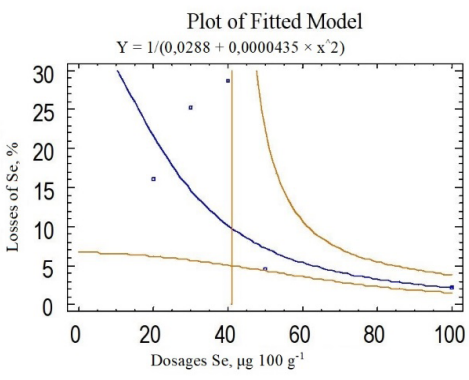

b) pre-ferment mode of production.

Figure 8. Dependence of losses of selenium during storage of unpackaged products on the dosage of the microelement.

The constructed models describe $98 \%$ (for the accelerated method) and $90 \%$ (for the pre-ferment method) variability of the variables with statistically significant correlation coefficients of 0.99 and 0.95 , respectively.

Comparison of the average values of selenium content in the unpackaged products of both methods of production by the Mann-Whitney test confirmed the absence of statistically significant differences between the distributions of the studied indicators at a significance level of 0.05 . Thus, there are no grounds for concluding that there are significant differences in losses of selenium in the storage of unpackaged articles of the investigated methods of production.

Studying the relationship between Se losses during the storage of packaged rolls and the initial dose in the accelerated production method established a significant and adequate correlation relationship. The constructed model describes $68 \%$ variability of the variables with a correlation coefficient of 0.83, which indicates a close relationship (Figure 9). 

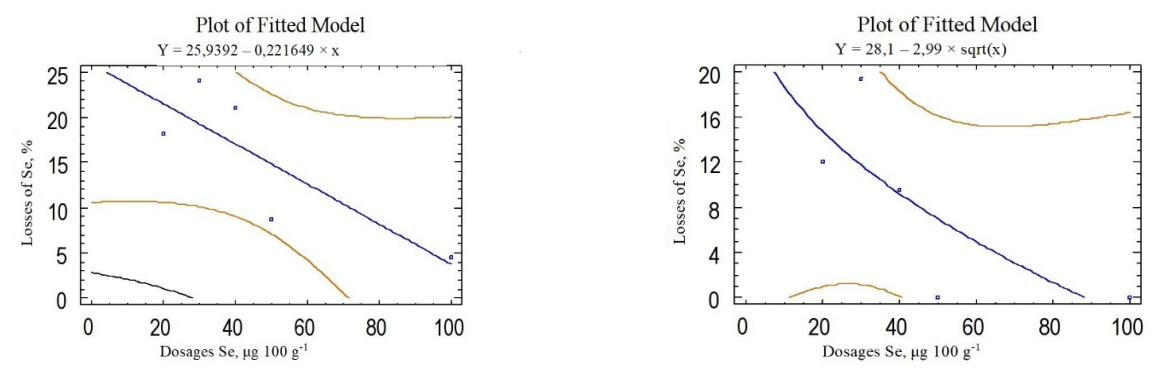

a) accelerated mode of production b) pre-ferment mode of production.

Figure 9. Dependence of selenium loss during storage of packaged products on the initial microelement dosage.

However, the model constructed for the pre-ferment method describes only $57 \%$ variability of the variables with a significant correlation coefficient of -0.75 (Figure 9), which also requires discussion when using the model obtained for the forecast (Byuyul and Cephil, 2005).

Comparing the average values of Se in the packaged products of both methods of production with the Mann-Whitney test showed the presence of statistically significant differences between their distributions at a significance level of 0.05 . Thus, it has been established that there are significant differences in Se losses during storage of packaged products of comparable production methods.

When comparing the average values of total Se losses in unpackaged rolls produced through the accelerated and pre-ferment production methods, the Mann-Whitney test showed no statistically significant differences between the distributions of the observed results at a significance level of 0.05 .

Comparison of the average values of total losses of Se in the packaged products of both production methods by the Mann-Whitney criterion showed the presence of statistically significant differences between the distributions of the studied indicators (Figure 10) at a significance level of 0.1. In this case, the products of the pre-ferment production method have less Se losses during 72 hours of storage. 


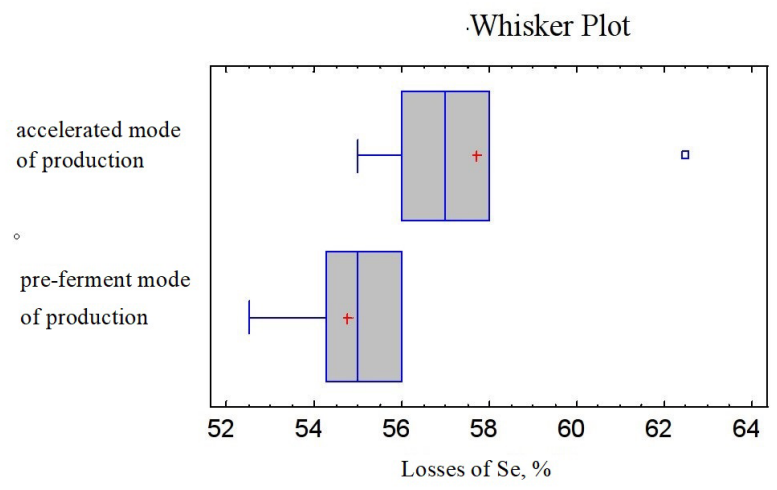

Figure 10. Comparison of the average values of total losses of selenium in packaged products of the accelerated and pre-ferment production methods.

\section{DISCUSSION}

It was established for the first time that when using selexen in the production of baked goods by the pre-ferment and accelerated methods, Se losses are within $45-55 \%$ of the applied dosage. These results do not contradict the data previously obtained by specialists from different countries. For instance, at Kemerovo Technological Institute of Food Science and Technology (Russia), Se losses during baking wheat bread cooked on baking yeast enriched with selenium (using $\mathrm{Na}_{2} \mathrm{SeO}_{3}$ ) are determined at the level of $50-60 \%$ of its initial amount (Mayurnikova et al., 2009). Scientists of the National Technical University (Ukraine) also determined the loss of $\mathrm{Se}$, which is part of $\mathrm{Na}_{2} \mathrm{SeO}_{3}$ used in the production of enriched wheat bread and sliced loaf, within 60\% (Ovsyannikova and Krichkovskaya, 2016).

In his book 'Selenium in Food and Health' (2006), C. Reilly explains selenium loss in the cooking process, stating that any heat treatment of organic products containing selenium is the main contributing factor to its loss. The evaporation temperature of selenium lies in the range of $180-230^{\circ} \mathrm{C}$ (at a pressure of $750-770 \mathrm{~mm} \mathrm{Hg}$ ), which corresponds to a baking temperature of $205 \pm 2^{\circ} \mathrm{C}$. Selenium losses can be attributed to the formation of volatile alkylselenides (Kudryavtsev, 1968; Zefirov, 1995).

A day after baking, unpacked goods obtained by the accelerated method see $2-24 \%$ Se losses, and those obtained by the pre-ferment method - $2-28 \%$. No statistically significant differences were established. By increasing initial dosage of selenium in the composition of selexen, the percentage of losses decreases. 
It was found that in packaged rolls produced through the pre-ferment

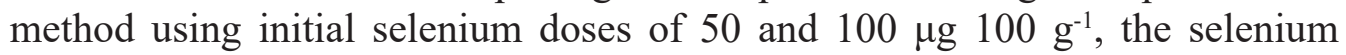
content at the end of the product shelf life ( 72 hours) does not change. With the remaining doses of selenium, losses are $9-19 \%$, and in packaged products obtained by the accelerated method, the Se losses are from 4 to $24 \%$ (when comparing selenium content immediately after baking) with the highest retention of the microelement at the initial dosages of 50 and $100 \mu \mathrm{g} 100 \mathrm{~g}^{-1}$.

\section{CONCLUSION}

Considering the lowest percentage of total Se losses, the optimal level of meeting adult daily requirements in selenium, and preferring the absence or presence of a package, we have established the following recommendations: in the production of baked goods without packaging, we recommend $40 \mu \mathrm{g}$ $100 \mathrm{~g}^{-1}$ selenium (selexen dosage of $174 \mu \mathrm{g} 100 \mathrm{~g}^{-1}$ ) for the accelerated method of production and $50 \mu \mathrm{g} 100 \mathrm{~g}^{-1}$ selenium $\left(220 \mu \mathrm{g} 100 \mathrm{~g}^{-1}\right.$ of selexen) for the pre-ferment method; in the manufacture of packaged baked goods - $40 \mu \mathrm{g} 100 \mathrm{~g}^{-1}$ selenium $\left(174 \mu \mathrm{g} 100 \mathrm{~g}^{-1}\right.$ selexen dosage) for the pre-ferment production method and $50 \mu \mathrm{g} 100 \mathrm{~g}^{-1}$ selenium $\left(220 \mu \mathrm{g} 100 \mathrm{~g}^{-1}\right.$ selexen $)$ for the accelerated production method.

\section{ACKNOWLEDGEMENT}

The work was supported by Act 211 of the Government of the Russian Federation, contract No.02.A03.21.0011.

\section{REFERENCES}

Aryee, A.N.A., and Boye, J.I. 2015. Current and emerging trends in the formulation and manufacture of nutraceuticals and functional food products. Nutraceutical and Functional Food Processing Technology. John Wiley \& Sons Inc. USA. 1-52 pp. https://doi.org/10.1002/9781118504956.ch1

Burtseva, T.I., Golubkina, N.A., Rock, A.V., and Korchina, T.Y. 2012. Evaluation of the content of selenium in wheat growing in various areas of the Orenburg region. Questions of biological, Medical and Pharmaceutical Chemistry. 10(6): 68-72.

Byuyul, A., and Cephil, P. 2005. SPSS: The art of information processing. Analysis of Statistical Data and the Restoration of Hidden Patterns. A translated from German language. Saint Petersburg, Russia: Diasoftyup LLC. 608 p. 
EFSA Panel on Dietetic Products, Nutrition and Allergies (NDA). 2014. Scientific opinion on dietary reference values for selenium. EFSA Journal. 12(10): 3846. https://doi.org/10.2903/j.efsa.2014.3759

Erdenetsogt, E., Golubkina, N.A., Nadegkin, S.M., Monhoo, B., and Batjargal, J. 2014. Health risk connected with the low selenium levels in foodstuffs of Mongolia. Environment and Natural Resources Research. 4(3): 192-203. https://doi.org/10.5539/enrr.v4n3p192

Fairweather-Tait, S.J., Bao, Y., Broadley, M.R., Collings, R.,Ford,D.,Hesketh,J.E., and Hurst, R. 2011. Selenium in human health and disease. Antioxidants and Redox Signaling. 14(7): 1337-1383. https://doi.org/10.1089/ars.2010. 3275

Fordyce, F.M. 2013. Selenium deficiency and toxicity in the environment. Essentials of Medical Geology. Berlin: Springer. 375-416 pp.

Glotova, I.A., Galochkina, N.A., and Kurchaeva, E.E. 2013. Selenium-deficient condition of the population and methods of alimentary correction. Food Industry. 12: 74-77.

Gupta, M., and Gupta, S. 2016. An overview of selenium uptake, metabolism, and toxicity in plants. Frontiers in Plant Science. 7: 1-14. https://doi. org/10.3389/fpls.2016.02074

Hart, D.J., Fairweather-Tait, S.J., Broadley, M.R., Dickinson, S.J., Foot, I., Knott, P., McGrath, S.P., Mowat, H., Norman, K., Scott, P.R., et al. 2011. Selenium concentration and speciation in biofortified flour and bread: Retention of selenium during grain biofortification, processing and production of Se-enriched food. Food Chemistry. 126(4): 1771-1778. https://doi.org/10.1016/j.foodchem.2010.12.079

Hu, Y., Mcintosh, G.H., and Young, G.P. 2012. Selenium-rich foods: a promising approach to colorectal cancer prevention. Current Pharmaceutical Biotechnology. 13(1): 165-172. https://doi.org/10.2174/1389201127988688 09

Ilyina, O.A. 2012. Bread is the basis of food rations for the Russian population. Bakery Products. 7: 14-15.

Ilyina, O.A., Balandina, A.S., and Iunikhina, E.V. 2013. An integrated approach to the management of bread quality. Food Industry. 2: 14-17.

Jablonska, E., and Vinceti, M. 2015. Selenium and human health: Witnessing a copernican revolution? Journal of Environmental Science and Health. Part C: Environmental, Carcinogenesis and Ecotoxicology. Reviews. 33: 328368. https://doi.org/10.1080/10590501.2015.1055163

Kodentsova, V.M., and Vrgesinskaya, O.A. 2008. Food products enriched with vitamins and minerals: their role in providing the body with micronutrients. Questions of Nutrition. 4: 16-25. 
Kodentsova, V.M., Vrzhesinskaya, O.A., and Spirichev, V.B. 2010. Justification of the level of enrichment of food products with vitamins and minerals. Questions of Nutrition. 1: 23-33.

Kudryavtsev, A.A. 1968. The Chemistry and Technology of Selenium and Tellurium. (in Russians). Metallurgizdat, Moscow. 211 p.

Lazo-Vélez, M.A., Chávez-Santoscoy, A., and Serna-Saldivar, S.O. 2015. Selenium-enriched breads and their benefits in human nutrition and health as affected by agronomic, milling and baking factors. Cereal Chemistry. 92(2): 134-144. https://doi.org/10.1094/CCHEM-05-14-0110-RW

Mahlapuu, R., Kullisaar, T., and Turk, S. 2014. Male infertility: decreased levels of selenium, zinc and antioxidants. Journal of Trace Elements in Medicine and Biology. 28(2): 179-185. https://doi.org/10.1016/j.jtemb.2013.12.005 Mayurnikova, L., Permyakova, A., Davydenko, N., and Asyakina, L. 2009. Enrichment of bread and bakery products with selenium. Bakery Products. 1: $38-40$.

Natasha, N., Shahid, M., Niazi, N.K., Khalid, S., Murtaza, B., Bibi, I., and Rashid, M.I. 2018. A critical review of selenium biogeochemical behavior in soilplant system with an inference to human health. Environmental Pollution. 234: 915-934. https://doi.org/10.1016/j.envpol.2017.12.019

Nociek, N.S., Gorchakova, N.O., and Belenichev, I.F. 2015. Selenium and nanoselenium: a role in the body and use in medical practice. Ukrainian Scientific and Medical Youth Magazine. 4(91): 129-133.

Ovsyannikova, T.A., and Krichkovskaya, L.V. 2016. The influence of lactic acid on quality of bakery products and loss of micronutrients in baking and storage. Food Science and Technology. 10(2): 37-41.

Rayman, M.P., Winther, K.H., Pastor-Barriuso, R., Cold, F., Thvilum, M., Stranges, S., Guallar, E., and Cold, S. 2018. Effect of long-term selenium supplementation on mortality: Results from a multiple-dose, randomized controlled trial. Circulation. 127: 46-54. https://doi.org/10.1016/j.freerad biomed.2018.02.015

Report on the study of the functional suitability of the domestic organic combination of selenium-selexen. 2000. Scientific-Production Enterprise 'Medbiofarm'. Obninsk: Medical Radiological Research Center. 30 p.

Reilly, C. 2006. Selenium in Food and Health. Springer Science+Business Media, LLC. New York, USA. 199 p.

Roman, M., Barbante, C., and Jitaru, P. 2014. Selenium biochemistry and its role for human health. Metallomics. 6(1): 25-54. https://doi.org/10.1039/ c3mt00185g

Skalickova, S., Milosavljevic, V., Cihalova, K., Horky, P., Richtera, L., and Adam, V. 2017. Selenium nanoparticles as a nutritional supplement. Nutrition. 33: 83-90. https://doi.org/10.1016/j.nut.2016.05.001 
Skurikhin, I.M., and Tutelyan, V.A. 1998. A guide to the methods of analyzing food quality and safety. Brandes, Medicine. Moscow.

Sobolev, O., Gutyj, B., Petryshak, R., Pivtorak, J., Kovalskyi, Y., Naumyuk, A., Petryshak, O., Semchuk, I., Mateusz, V., Shcherbatyy, A., et al. 2018. Biological role of selenium in the organism of animals and humans. Ukrainian Journal of Ecology. 8(1): 654-665.

Spirichev, V.B., Poznyakovskiy, V.M., and Trichina, V.V. 2012. Enrichment of food with micronutrients is a reliable way to optimize their consumption. Food Industry. 2: 9-15.

Stoffaneller, R., and Morse, N.L. 2015. A review of dietary selenium intake and selenium status in Europe and the Middle East. Nutrients. 7(3): 1494-537. https://doi.org/10.3390/nu7031494

Tarasova, V.V. 2014. Application of physiologically functional ingredients in the production of bakery products. Food Industry. 3: 34-41.

Tutelyan, V.A. 2009. Norms of Physiological needs in energy and food substances for various populations of the Russian Federation. Nutrition Issues. 1: 4-16.

Vinceti, M., Filippini, T., Del Giovane, C., Dennert, G., Zwahlen, M., Brinkman, M., Zeegers, M.P.A., Horneber, M., D'Amico, R., and Crespi, C.M. 2018. Selenium for preventing cancer. Cochrane Database of Systematic Reviews. 1(4): 127-156. https://doi.org/10.1002/14651858. CD005195.pub4

Zefirov, N.S. 1995. Chemical encyclopedia: in 5 volumes. Encyclopedia. 4: 311-639.

Zhang, P., Guan, X., Yang, M., Zeng, L., and Liu, C. 2018. Roles and potential mechanisms of selenium in countering thyrotoxicity of DEHP. Science of the Total Environment. 619-620: 732-739. https://doi.org/10.1016/j. scitotenv.2017.11.169 